\title{
Investigation of Two-Dimensional Ultrasonic Surface Burnishing Process on 7075-T6 Aluminum
}

\author{
Zhenyu Zhou ${ }^{1,2}$, Qiuyang Zheng ${ }^{1,2}$, Cong Ding ${ }^{1,2}$, Guanglei Yu ${ }^{1,2}$, Guangjian Peng ${ }^{1,2}$ and Zhongyu Piao ${ }^{1,2^{*}}$ (1)
}

\begin{abstract}
A novel two-dimensional ultrasonic surface burnishing process (2D-USBP) is proposed. 7075-T6 aluminum samples are processed by a custom-designed 2D-USBP setup. Parameter optimization of 2D-USBP is conducted to determine the best processing strategy of 7075-T6 aluminum. A uniform design method is utilized to optimize the 2D-USBP process. $U_{13}\left(13^{3}\right)$ and $U_{7}\left(7^{2}\right)$ tables are established to conduct parameter optimization. Burnishing depth, spindle speed, and feed rate are taken as the control parameters. The surface roughness and Vickers hardness are taken as the evaluation indicators. It establishes the active control models for surface quality. Dry wear tests are conducted to compare the wear-resistance of the 2D-USBP treated sample and the original sample. Results show that the machining quality of 2D-USBP is best under $0.24 \mathrm{~mm}$ burnishing depth, $5000 \mathrm{r} / \mathrm{min}$ spindle speed, and $25 \mathrm{~mm} / \mathrm{min}$ feed rate. The surface roughness $S_{a}$ of the sample is reduced from 2517.758 to $50.878 \mathrm{~nm}$, and the hardness of the sample surface is improved from 167 to $252 \mathrm{HV}$. Under the lower load, the wear mechanism of the 2D-USBP treated sample is mainly abrasive wear accompanied by delamination wear, while the wear mechanism of the original sample is mainly delamination wear. Under the higher load, the accumulation of frictional heat on the sample surface transforms the wear mechanisms of the original and the 2D-USBP treated samples into thermal wear.
\end{abstract}

Keywords: Two-dimensional ultrasonic-assisted burnishing, Uniform design, Regression analysis, Wear behavior

\section{Introduction}

7075-T6 aluminum is widely used in automobiles, aerospace, and other fields due to its low density, high processability, high specific elastic modulus, and high specific strength [1-3]. Aluminum is an excellent structure material, but its surface performance is not very well, whose wear-resistance needs to be improved for broader industry applications [4-6]. Gradient nanostructure is recognized as an effective surface structure to improve the wear-resistance of metal [7-11]. There are many methods to machine the gradient nanostructure on the material surface, such as laser shot peening

\footnotetext{
*Correspondence: piaozy@zjut.edu.cn

${ }^{1}$ College of Mechanical Engineering, Zhejiang University of Technology, Hangzhou 310012, China

Full list of author information is available at the end of the article
}

[12], high energy shot peening [13], surface mechanical attrition treatment [14], and wire-brush [15]. Nonetheless, the methods mentioned above have disadvantages, which are easy to produce micro-cracks, unsatisfactory surface roughness, and thinner gradient nanostructure. Surface burnishing can realize continuous and controlled machining to produce gradient nanostructure with uniform thickness and smooth surfaces [16-18].

Researchers have achieved many research results in the field of surface burnishing. Lin et al. [19] found that surface burnishing can improve the comprehensive properties of the material surface, including hardness, surface roughness, and residual compressive stress. Rotella et al. [20] found that surface burnishing always improves the wear resistance of the components when cryogenic cooling and coated tools were employed. Bozdana et al. [21] introduced the ultrasonic field into the cryo-burnishing process to 
machine Ti-6Al-4V, improved the surface hardness and the residual compressive stress of the sample with ideal surface roughness.

In the previous work of the research group, numerical simulation methods were introduced to investigate the varieties of grain sizes in the ultrasonic-assisted surface burnishing process and reveal the relevant mechanism. The gradient nanostructure layer was machined on 7075-aluminum samples by ultrasonic-assisted surface burnishing process. The introduction of ultrasonic vibration increases the thickness of the gradient nanostructure [22, 23]. Nevertheless, ultrasonic-assisted surface burnishing process has a higher coefficient of friction (COF) than surface burnishing process, which not conducive to surface roughness [24]. In the machining process, the two-dimensional vibration can further optimize the cycle of stress loading, lessen the fluctuation of the machining force, and reduce COF. However, up to date, seldom researches have been committed to exploring the plane two-dimensional ultrasonic surface burnishing process (2D-USBP). Material surface integrity is sensitive to 2D-USBP processing parameters. At present, the setting of processing parameters mainly depends on experience, resulting in large fluctuations in processing quality and low consistency. In order to improve the stability of the machining process, it is necessary to conduct an in-depth study on the influence of related processing parameters in the machining process.

In the present study, the uniform design method is proposed to optimize the processing parameters of 2D-USBP. The surface roughness $S_{\mathrm{a}}$ and Vickers hardness of samples are characterized by a white light interferometer and Vickers hardness tester, respectively. Subsequently, active control models of surface roughness $S_{\mathrm{a}}$ and Vickers hardness are established based on uniform design tables. The dry wear properties of the sample machined based on the optimized processing parameters are characterized by a scanning electron microscope (SEM) and a confocal laser scanning microscope (CLSM), then the corresponding mechanisms are discussed.

\section{Uniform Design and Experiment}

\subsection{Experiment Material and Processing Equipment}

The detailed compositions of the 7075-T6 aluminum (30 $\mathrm{mm} \times 50 \mathrm{~mm} \times 10 \mathrm{~mm}$ ) in the experiment are listed in Table 1. The surface roughness $S_{\mathrm{a}}$ of the sample used in this experiment is $2517.7 \mathrm{~nm}$, and the surface Vickers hardness is $167 \mathrm{HV}$.
The schematic diagram and photo of the 2D-USBP setup are shown in Figure 1. Figure 1(a) shows the customer-designed burnishing tool, where eleven balls are evenly distributed in the circumferential direction of the lower end. Under the action of the downward pressure, the balls make pure rolling contact with the sample, causing plastic flow on the surface and reducing scratches. Figure 1(b) shows the two-dimensional ultrasonic vibration platform that directly applies two-dimensional ultrasonic vibration to the sample with a vibration frequency of $20 \mathrm{kHz}$ and an amplitude of $9 \mu \mathrm{m}$, resulting in the reduction of the machining force between the tool and the sample. Figure 1 (c) shows the photo of the 2D-USBP device that was installed on an XK-714 CNC milling machine, of which the displacement accuracy is $1 \mu \mathrm{m}$, to precisely control the machining process according to the program. The essence of 2D-USBP is the surface plastic deformation caused by the impact and rolling contact

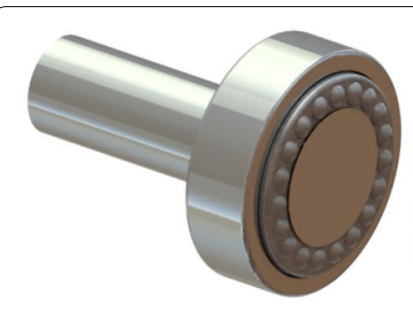

a Plane burnishing tool

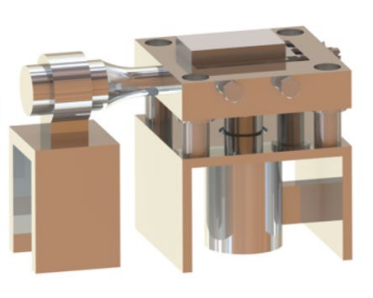

b Two-dimensional ultrasonic vibration platform

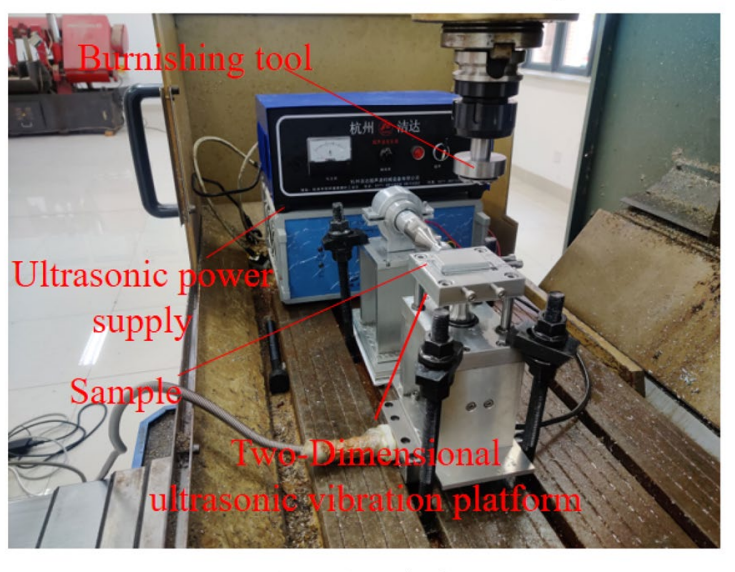

c 2D-USBP device

Figure 1 Schematic diagram and photo of the 2D-USBP setup. a Plane burnishing tool. b Two-dimensional ultrasonic vibration platform. c 2D-USBP device

Table 1 The detailed compositions of 7075-T6 Aluminum

\begin{tabular}{llllllllll}
\hline Chemical element & Si & Fe & Cu & Zn & Ti & Mn & Mg & Cr & Al \\
\hline Content (Wt $\%)$ & 0.36 & 0.42 & 1.58 & 5.8 & 0.11 & 0.17 & 2.45 & 0.225 & Bal. \\
\hline
\end{tabular}


between the burnishing ball and the machined surface. The surface peaks undergo plastic flow to fill the free valleys, resulting in reducing the surface roughness. Plastic deformation activates dislocation movement and dislocation proliferation, which changes the surface microstructure (dislocations, grains, phase structure) and increases the hardness.

\subsection{Uniform Design Method}

In order that the mapping relationship between processing parameters and surface quality is considered comprehensively, active control models of surface quality were established based on uniform design [25, 26]. Burnishing depth, spindle speed, and feed rate were introduced as control parameters. Meanwhile, the surface roughness $S_{\mathrm{a}}$, measured by the white light interferometer with a measurement range of $500 \times 500 \mu \mathrm{m}$, and Vickers hardness, measured by the HV-1000 hardness tester under $50 \mathrm{~g}$ load and $10 \mathrm{~s}$ loading time, were used evaluation indicators. Three samples were machined for each set of parameters, and five measurement points were taken for each sample. Then, the average value was taken as evaluation indicators. Table 2 lists the available range of 2D-USBP processing parameters. A $U_{13}\left(13^{3}\right)$ uniform design table, listed in Table 3, was established according to Table 2.

After 2D-USBP the sample, acetone was used to remove the oil on the sample surface. The surface roughness $S_{\text {a }}$ and the Vickers hardness were characterized, whose preliminary regression equations were established based on the characterization results. In order to select the optimal processing parameters more accurately, a $U_{7}\left(7^{2}\right)$ uniform design table, listed in Table 4, was further established based on the preliminary regression equations.

\subsection{Wear Test}

Dry wear tests were conducted to compare the wear behavior of the original sample and the 2D-USBP treated sample by a CETR UMT-3 ball-on-disc tribometer. The upper sample was a GCr15 steel ball with a diameter of $8 \mathrm{~mm}$ and hardness of 65 HRC. Three parallel dry wear experiments of each sample were conducted under $5 \mathrm{~N}$, $15 \mathrm{~N}, 25 \mathrm{~N}$, and $35 \mathrm{~N}$ loads, respectively. During testing, the frequency, reciprocating stroke, and test time were

Table 2 Available range of 2D-USBP processing parameters

\begin{tabular}{lll}
\hline Process parameter & Value & Reason \\
\hline Burnishing depth $(\mathrm{mm})$ & $0.03-0.39$ & $<0.03$, the sample cannot reach the yield strength \\
Spindle speed $(\mathrm{r} / \mathrm{min})$ & $200-5000$ & $>0.39$, the sample produces debris \\
& & $<200$, noticeable feed marks appear on the \\
& surface of the sample \\
Feed rate $(\mathrm{mm} / \mathrm{min})$ & $10-70$ & 6000 is the upper limit of the milling machine \\
& & $<10$, the processing efficiency is low \\
& & $>70$, the uniformity of the surface is reduced
\end{tabular}

Table $3 U_{13}\left(13^{3}\right)$ Uniform design table

\begin{tabular}{|c|c|c|c|c|c|c|c|c|}
\hline Serial number & $\begin{array}{l}\text { Burnishing depth } \\
(\mathrm{mm})\end{array}$ & $\begin{array}{l}\text { Spindle speed } \\
\text { (r/min) }\end{array}$ & $\begin{array}{l}\text { Feed rate }(\mathrm{mm} / \\
\text { min) }\end{array}$ & BD & SS & FR & $\begin{array}{l}\text { Surface roughness } \\
S_{a}(n m)\end{array}$ & $\begin{array}{l}\text { Vickers } \\
\text { hardness } \\
\text { (HV) }\end{array}$ \\
\hline 1 & 0.03 & 3400 & 60 & 1 & 17 & 12 & 598.22 & 190 \\
\hline 2 & 0.06 & 1400 & 45 & 2 & 7 & 9 & 625.04 & 184 \\
\hline 3 & 0.09 & 5000 & 30 & 3 & 25 & 6 & 202.48 & 222 \\
\hline 4 & 0.12 & 3000 & 15 & 4 & 15 & 3 & 204.35 & 201 \\
\hline 5 & 0.15 & 1000 & 70 & 5 & 5 & 14 & 120.58 & 202 \\
\hline 6 & 0.18 & 4600 & 55 & 6 & 23 & 11 & 206.29 & 214 \\
\hline 7 & 0.21 & 2600 & 40 & 7 & 13 & 8 & 97.7 & 219 \\
\hline 8 & 0.24 & 600 & 25 & 8 & 3 & 8 & 110.17 & 234 \\
\hline 9 & 0.27 & 4200 & 10 & 9 & 21 & 2 & 152.33 & 221 \\
\hline 10 & 0.30 & 2200 & 65 & 10 & 11 & 13 & 273.01 & 224 \\
\hline 11 & 0.33 & 200 & 50 & 11 & 1 & 10 & 248.89 & 232 \\
\hline 12 & 0.36 & 3800 & 35 & 12 & 19 & 7 & 249.89 & 244 \\
\hline 13 & 0.39 & 1800 & 20 & 13 & 9 & 4 & 184.63 & 175 \\
\hline
\end{tabular}


Table 4 Surface roughness $S_{\mathrm{a}}$ prediction $(\mathrm{nm})$

\begin{tabular}{|c|c|c|c|c|c|c|c|c|c|}
\hline \multirow[t]{2}{*}{ BD } & \multicolumn{9}{|l|}{ SS } \\
\hline & 17 & 18 & 19 & 20 & 21 & 22 & 23 & 24 & 25 \\
\hline 7 & 92.83 & 92.97 & 93.37 & 94.00 & 94.85 & 95.90 & 97.15 & 98.56 & 100.15 \\
\hline 8 & 97.93 & 99.42 & 101.17 & 103.15 & 105.35 & 107.76 & 110.35 & 113.12 & 116.05 \\
\hline 9 & 116.70 & 119.54 & 122.64 & 125.97 & 129.52 & 133.27 & 137.22 & 141.33 & 145.62 \\
\hline 10 & 146.91 & 151.10 & 155.55 & 160.23 & 165.13 & 170.23 & 175.53 & 180.99 & 186.63 \\
\hline 11 & 186.88 & 192.42 & 198.22 & 204.25 & 210.50 & 216.96 & 223.60 & 230.42 & 237.40 \\
\hline
\end{tabular}

set at $2 \mathrm{~Hz}, 5 \mathrm{~mm}$, and $1200 \mathrm{~s}$, respectively. The wear scars were characterized by SEM and CLSM.

\section{Results}

\subsection{Establish Regression Equation}

In order to avoid that large-value parameter annihilate small-value parameter information, the values of the three parameters were linearly transformed, whose result is shown in Eqs. (1), (2), (3), respectively. The measurement results of the surface roughness $S_{\mathrm{a}}$ and the Vickers hardness are shown in Table 3. Figure 2 shows the experimental results of the $U_{13}\left(13^{3}\right)$ uniform design table.

$$
\begin{aligned}
& \mathrm{BD}=\text { burnishing depth } / 0.03, \\
& \mathrm{SS}=\text { spindle speed } / 200, \\
& \mathrm{FR}=\text { feed rate } / 5 .
\end{aligned}
$$

Based on Table 3, the results were fitted to establish a surface roughness regression equation and a hardness regression equation.

The surface roughness regression equation is given as:

$$
\begin{aligned}
R= & 207.018 \times \mathrm{BD}-1230.962 \times \mathrm{BD}^{0.5} \\
& -34.822 \times(\mathrm{SS} \times \mathrm{FR})^{0.5} \\
& +0.27 \times \mathrm{BD} \times \mathrm{SS} \times \mathrm{FR}+2060.914
\end{aligned}
$$

The hardness regression equation is given as:

$$
\begin{aligned}
V= & -2.311 \times \mathrm{BD}^{2}+48.973 \times \mathrm{BD}+2.556 \times \mathrm{SS} \\
& +1.491 \times \mathrm{BD} \times \mathrm{SS}-1.134 \times \mathrm{SS} \times \mathrm{FR} \\
& -50.753 \times \mathrm{FR}^{0.5}-46.603 \times(\mathrm{BD} \times \mathrm{SS})^{0.5} \\
& +36.294 \times(\mathrm{SS} \times \mathrm{FR})^{0.5}+165.428 .
\end{aligned}
$$

\subsection{Dry Wear Test}

Figure 3 shows the average of COF at the steady stage in dry wear tests. Under various loads, COF of the 2D-USBP treated sample is smaller than that of the

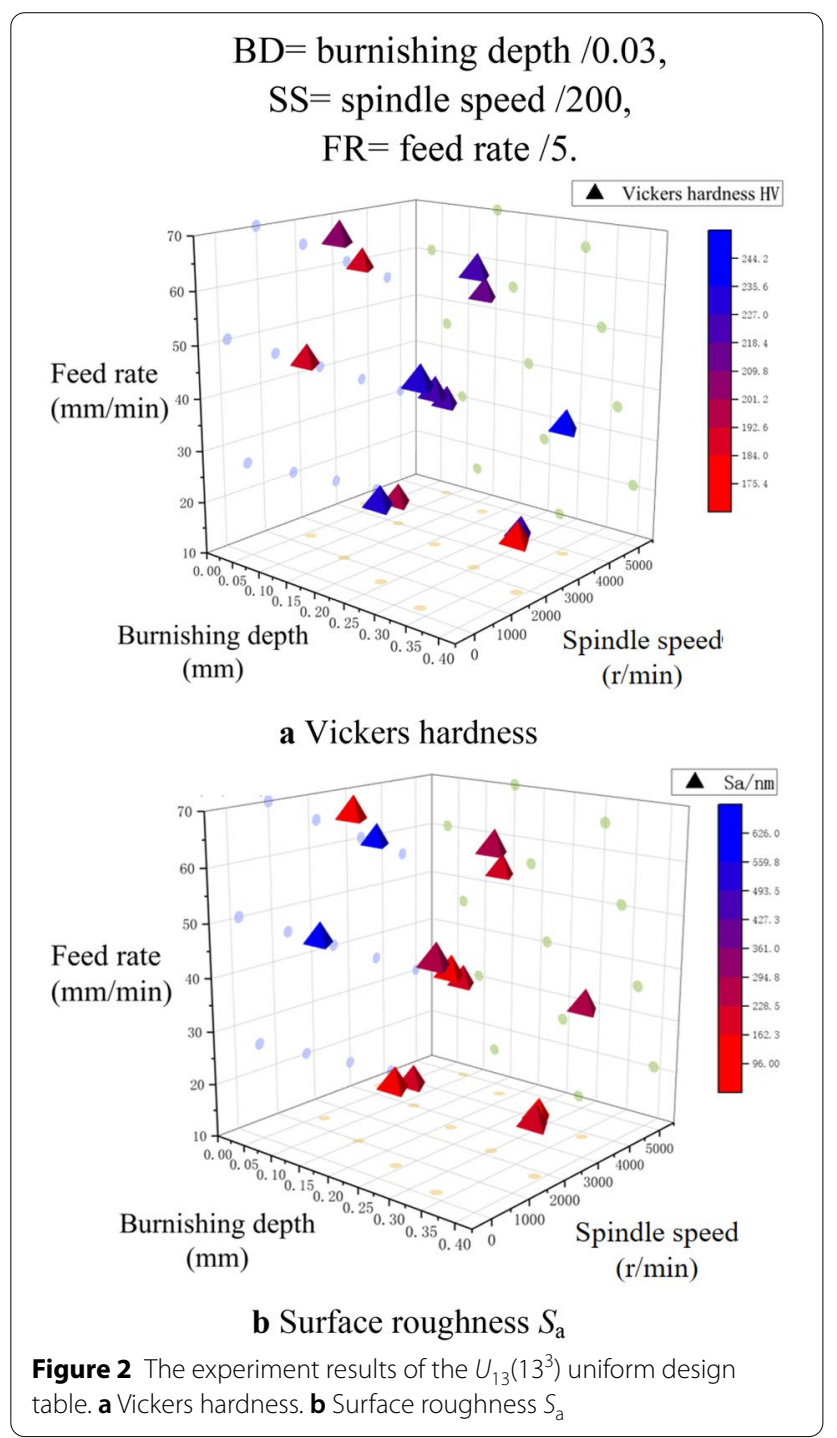

original sample, and COF of the two has a similar trend with the increase of load. With the increase of the load, COF of the 2D-USBP treated sample decreased from 0.42 to 0.38 and stabilized around 0.38 , while COF of the original sample decreased from 0.45 to 0.41 and 


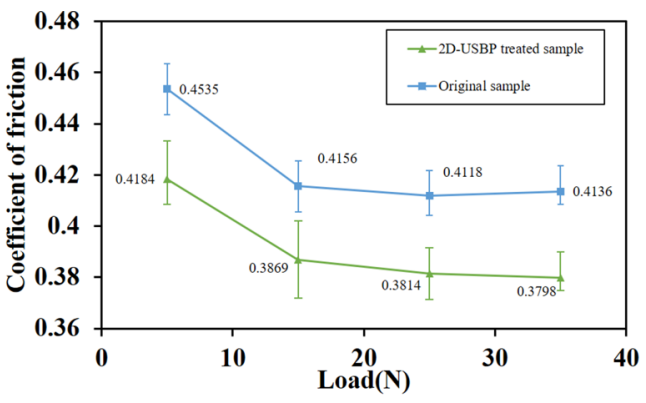

a Average

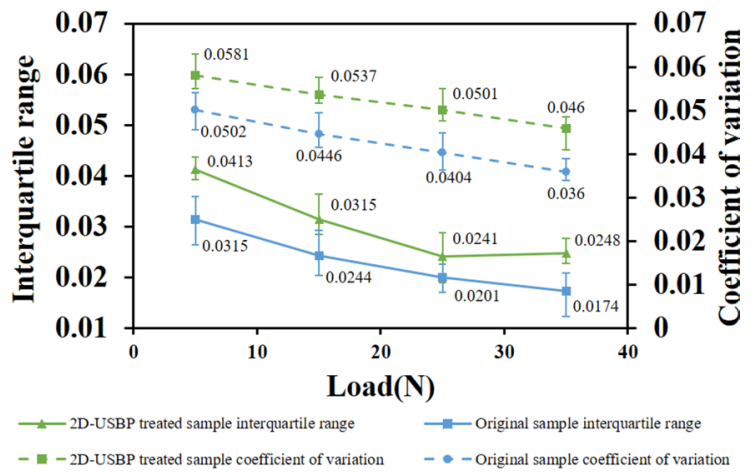

b Interquartile range and coefficient of variation

Figure $\mathbf{3}$ Statistical values of COF. a Average. $\mathbf{b}$ Interquartile range and coefficient of variation stabilized around 0.41 . The coefficient of variation, interquartile range of both decreased with the load increased. Under the same load, the coefficient of variation and interquartile range of the original sample are smaller than those of the 2D-USBP treated sample.

Figure 4 shows the cross-section of the wear scars measured by CLSM. Figure 5 shows the cross-section size of the wear scars (the maximum wear scar area, the maximum wear scar depth, and the maximum wear scar width) of the original sample and the 2D-USBP treated sample. Three samples were selected under the same test parameters, and the maximum size of each wear scar was recorded. Under the lower load $(5 \mathrm{~N}$, $15 \mathrm{~N}$, and $25 \mathrm{~N}$ ), the wear scar size of the original sample is larger than that of the 2D-USBP treated sample. Under the higher load $(35 \mathrm{~N})$, the wear scar size is close to the original sample and the 2D-USBP treated sample. The wear scar size of the 2D-USBP treated sample increased approximately linearly under the lower load. Similar trends existed in the original sample. When the load is $35 \mathrm{~N}$, the increase rate of both wear scar sizes suddenly increases. Figure 6 shows the wear weight loss of the original sample and the 2D-USBP treated sample measured by electronic balance. Under the lower load, the wear weight loss of the 2D-USBP treated sample is less than that of the original sample, and the gap between the two increases with the increase of the load. Under the higher load, the original sample and the 2D-USBP treated sample have similar wear weight loss.

Figure 7 shows the wear scar morphologies of the original sample and the 2D-USBP treated sample by SEM. Figures 7(a), 7(c), 7(e) show that a large number of plough-like wear marks parallel to the sliding direction due to abrasive wear on the surface of the 2D-USBP treated sample, accompanied by irregular peeling areas caused by delamination wear. As the load increases, the degree of abrasive wear increases first and then decreases. Figure $7(\mathrm{~g})$ shows that under $35 \mathrm{~N}$ load, the 2D-USBP treated sample has a smoother wear scar, a smearing phenomenon caused by thermal wear. Figure 8 also shows that under the $5 \mathrm{~N}$ load, the wear scar of the 2D-USBP treated sample is mainly caused by abrasive wear accompanied by delamination wear. Meanwhile, under the $35 \mathrm{~N}$ load, the wear scar is mainly caused by thermal wear and accompanied by delamination wear. Figures 7(b), 7(d), and 7(f) show that under the load of $5 \mathrm{~N}, 15 \mathrm{~N}$, and $25 \mathrm{~N}$, many irregular peeling areas appear on the surface of the original sample due to delamination wear. Figure $7(\mathrm{~h})$ shows that under the $35 \mathrm{~N}$ load, the surface wear scar of the original sample is mainly caused by thermal wear.

\section{Discussion}

\subsection{Parameter Optimization}

Regression equations based on uniform design cannot be extrapolated, to the extent that the extremum can only be found in the regression equation domain. According to the regression Eq. (4), $\mathrm{BD}=7, \mathrm{SS}=17$, and $\mathrm{FR}=5$ are regarded as the extremum of the $U_{13}\left(13^{3}\right)$ surface roughness regression equation, which differs from the actual extreme value of only $0.39 \%$. According to the regression Eq. (5), $\mathrm{BD}=11, \mathrm{SS}=25$, and $\mathrm{FR}=5$ are regarded as extremum of the $U_{13}\left(13^{3}\right)$ hardness regression equation, which differs from the actual extreme value of only $0.05 \%$.

Figure 9 and Figure 10 show that the $U_{13}\left(13^{3}\right)$ hardness regression equation and the $U_{13}\left(13^{3}\right)$ surface roughness regression equation at $\mathrm{FR}=4,5$, and 6 . When $\mathrm{FR}$ is in the range of 4-6, there is only a slight difference in the shape and size of the hardness model and the surface roughness model. Both models are insensitive to changes near FR = 5 and more sensitive to BD and SS. It can be considered that FR and BD, SS have no interactivity near $F R=5$. Considering the hardness and surface roughness comprehensively, the surface machining quality of the material is close to the optimum value when $\mathrm{FR}=5$. Furthermore, Figure 9 shows that there is a strong interaction between $\mathrm{SS}$ and $\mathrm{BD}$, where it have two better regions, which are 


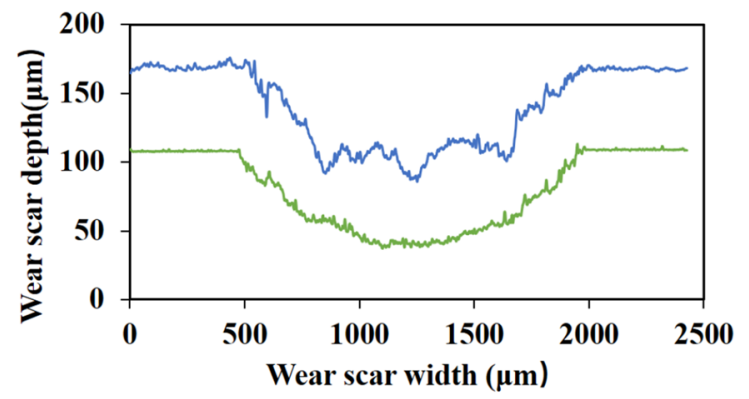

-2D-USBP treated sample - Original sample

a $5 \mathrm{~N}$ load

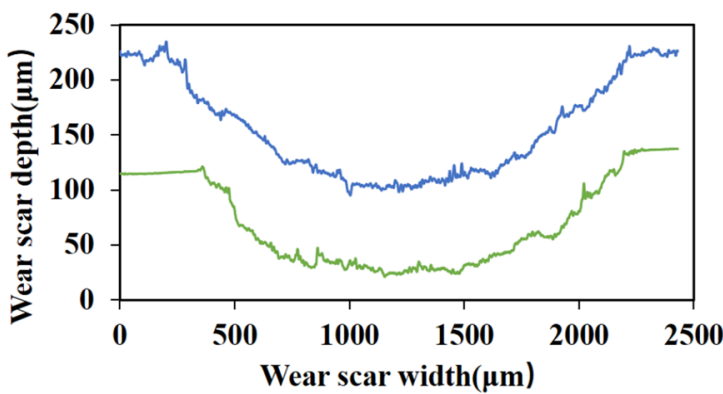

-2D-USBP treated sample - Original sample c $25 \mathrm{~N}$ load

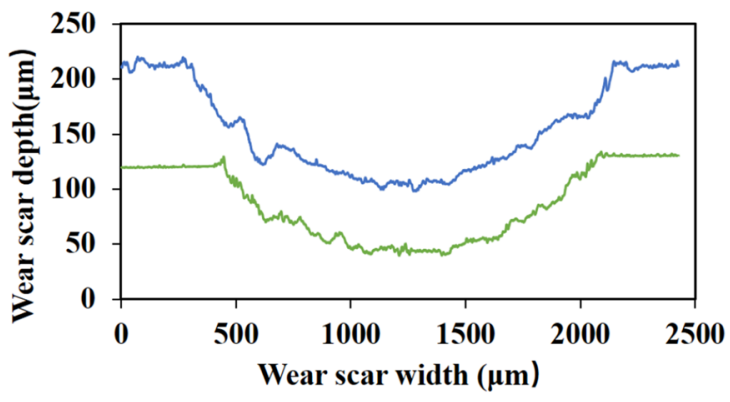

-2D-USBP treated sample — Original sample

b $15 \mathrm{~N}$ load

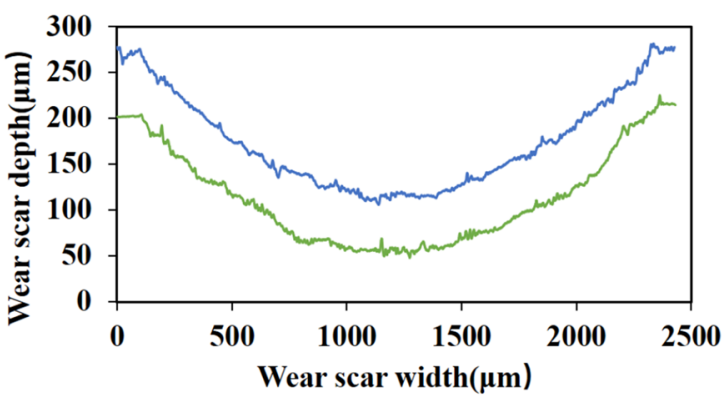

-2D-USBP treated sample -Original sample

d $35 \mathrm{~N}$ load

Figure 4 Cross-section of dry wear scars. a 5 N load. b 15 N load. c 25 N load. d 35 N load

$\mathrm{BD}=7-12, \mathrm{SS}=1-3$, and $\mathrm{BD}=7-11, \mathrm{SS}=22-25$. Figure 10 shows that BD has a more significant effect on $S_{\mathrm{a}}$, with better results at $\mathrm{BD}=5-10, \mathrm{SS}=5-25$. In order to establish more accurate regression equations. Take $\mathrm{BD}=$ $[7,8,9,10,11]$, SS $=[17,18,19,20,21,22,23,24,25]$, $\mathrm{FR}=5$, then solve regression Eqs. (4), (5). The solution results are shown in Tables 4 and 5.

Table 4 shows that when $\mathrm{BD}=7, S_{\mathrm{a}}$ grows slowly with the increases of $\mathrm{SS}$. When $\mathrm{BD}=7, \mathrm{SS}=25$, the predicted value of $S_{\mathrm{a}}$ is only $7.89 \%$ larger than the extremum. Table 5 shows that when $\mathrm{SS}=25$, the hardness decreases slowly with the decrease of $\mathrm{BD} . \mathrm{When} \mathrm{BD}=7, \mathrm{SS}=25$, the hardness prediction value is only $8.06 \%$ smaller than the extremum. Considering surface roughness and hardness comprehensively, $\mathrm{BD}=7, \mathrm{SS}=25$, and $\mathrm{FR}=5$ are the better parameters of surface machining quality. A new $U_{7}\left(7^{2}\right)$ uniform design table was established with $\mathrm{BD}=7$, $\mathrm{SS}=25$, and $\mathrm{FR}=5$ to find the optimal combination of test conditions further. Table 6 lists the $U_{7}\left(7^{2}\right)$ uniform design table. Figure 11 shows the $U_{7}\left(7^{2}\right)$ uniform design experiment results.
Based on Table 6, the results were fitted to establish a surface roughness regression equation and a hardness regression equation.

The surface roughness regression equation is given as:

$$
\begin{aligned}
R= & 10.725 \times \mathrm{BD}^{2}+1.998 \times \mathrm{SS}^{2}-171.793 \\
& \times \mathrm{BD}-101.691 \times \mathrm{SS}+2055.624 .
\end{aligned}
$$

The hardness regression equation is given as:

$$
\mathrm{V}=-4.568 \times \mathrm{BD}^{2}+72.596 \times \mathrm{BD}-35.356 .
$$

Table 7 shows the significance analysis for two regression equations. The coefficient of determination $R^{2}$ of the surface roughness regression equation is 0.997 . The sum of squares of $S_{a}$ regression explains $99.7 \%$ of the total sum of squares of the model, and the equation fits well. The significance of Eq. (6) is less than one-thousandth, and the model confidence is high. From the results of Table 7, the coefficient of determination $R^{2}$ of the hardness regression equation is 0.810 . The sum of squared 


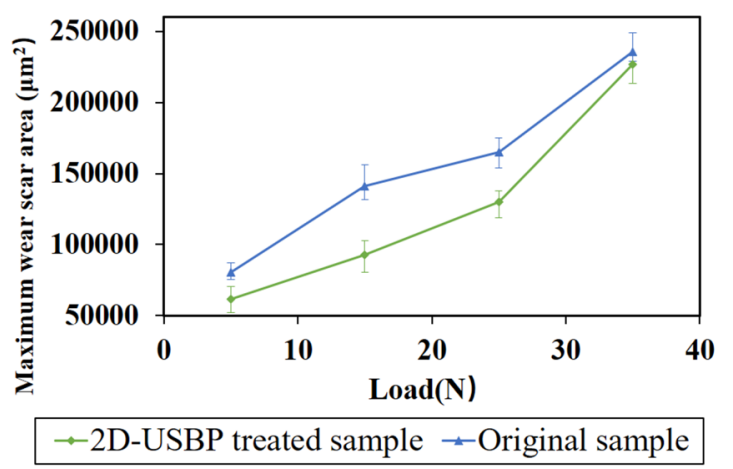

a Maximum wear scar area

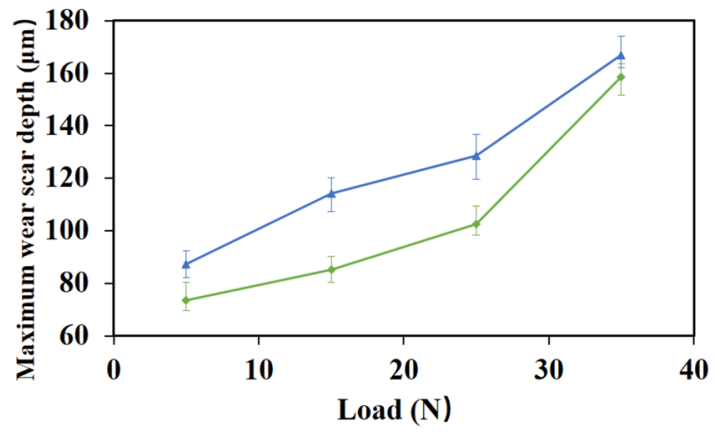

$\rightarrow-2$ D-USBP treated sample $\rightarrow$-Original sample

b Maximum wear scar depth

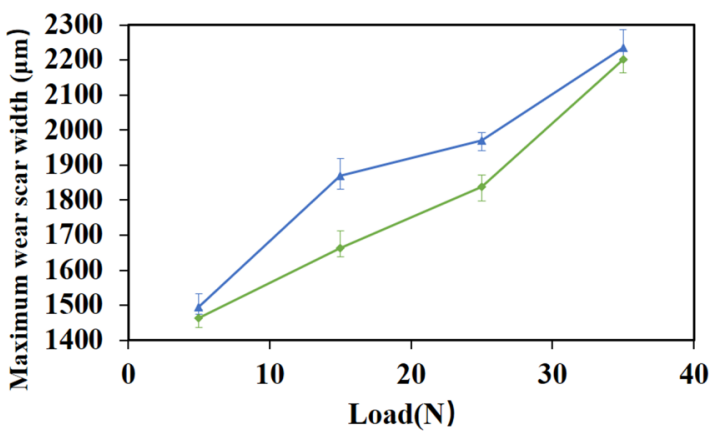

$\rightarrow-2$ D-USBP treated sample $\rightarrow$ Original sample

\section{c Maximum wear scar width}

Figure 5 Wear scar cross-section size of the original sample and the 2D-USBP treated sample. a Maximum wear scar area. b Maximum wear scar depth. c Maximum wear scar width

regressions of hardness explains that $81.0 \%$ of the total square sum of the models, and the degree of equation fitting is within the acceptance range. The significance of Eq. (7) is $3.6 \%$, and the model confidence is high.

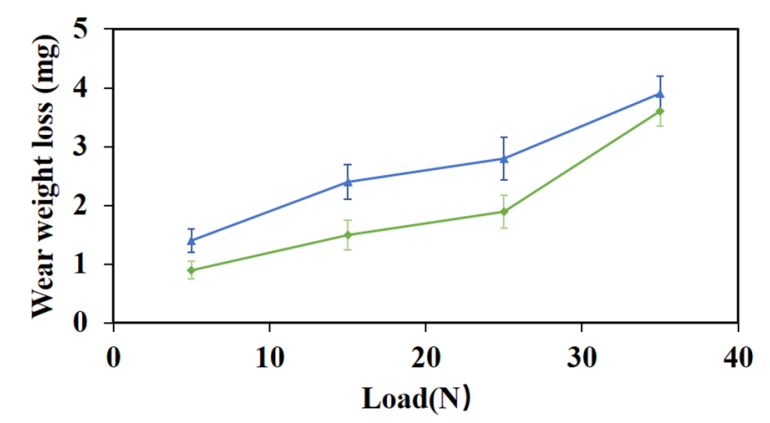

-2D-USBP treated sample - Original sample

Figure 6 Wear weight loss of the original sample and the 2D-USBP treated sample

Figures 12 and 13 show the $U_{7}\left(7^{2}\right)$ surface roughness regression equation and the $U_{7}\left(7^{2}\right)$ hardness regression equation. When $\mathrm{BD}=8, \mathrm{SS}=25$, the two are close to the extremum, whose extremums are $R=74.155 \mathrm{~nm}$, $V=253.06 \mathrm{HV}$. Therefore, the processing quality of 2D-USBP is best under $0.24 \mathrm{~mm}$ burnishing depth, $5000 \mathrm{r} / \mathrm{min}$ spindle speed, and $25 \mathrm{~mm} / \mathrm{min}$ feed rate.

Figure 14 shows the 3-D profile of the 7075-T6 aluminum surface before and after 2D-USBP. After 2D-USBP, surface roughness $S_{\mathrm{a}}$ of the sample is reduced from $2517.758 \mathrm{~nm}$ to $50.878 \mathrm{~nm}$, and the Vickers hardness is improved from 167 to $252 \mathrm{HV}$. The original texture of the sample surface disappeared, and the surface became flat.

\subsection{Wear Behavior}

When the friction pairs slide relative to each other, the two surfaces are subject to tangential resistance (friction) at the contact point due to mechanical engagement and molecular attraction. Therefore, the frictional resistance during dry wear comprises two parts: the adhesion resistance and the plough resistance, of which adhesion resistance dominates. According to the modified adhesion-plough friction theory, the friction force comprises adhesion force and plough force [27].

$$
F=T+P_{e}=A \tau_{b}+S p_{e}
$$

where $T$ is the shear stress, $A$ is the actual contact area, $\tau_{b}$ is the shear strength of the adhesion point, $P_{e}$ is the plough force, $S$ is the ploughed area, and $p_{e}$ is the plough force per unit area.

2D-USBP increases the surface hardness and smooths the sample surface, reducing the actual contact area between the friction pairs and the ploughed area. Therefore, COF of the 2D-USBP treated sample is lower than 


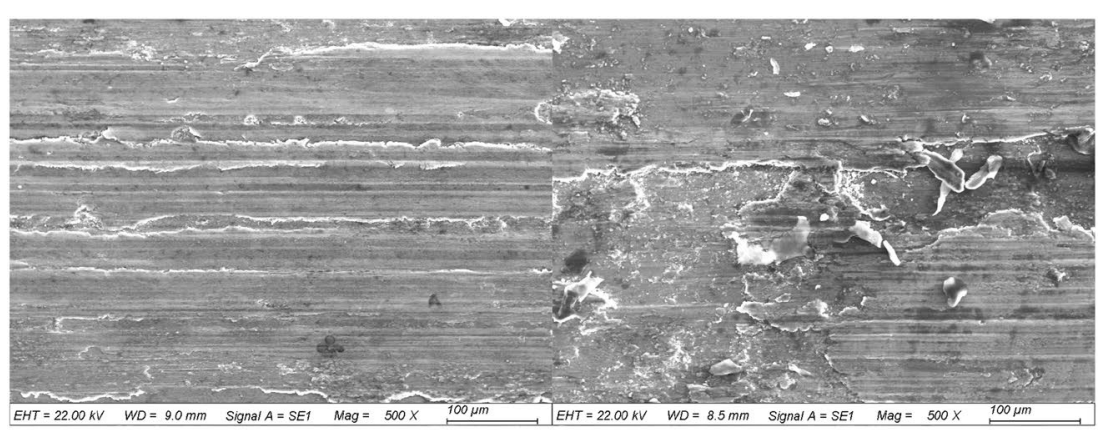

a $5 \mathrm{~N} 2 \mathrm{D}$-USBP treated sample b $5 \mathrm{~N}$ original sample

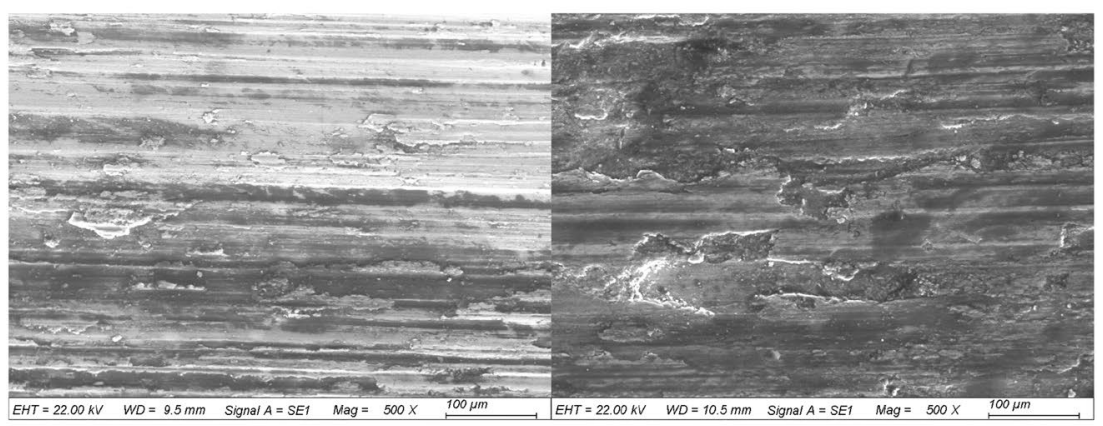

c 15 N 2D-USBP treated sample d $15 \mathrm{~N}$ original sample

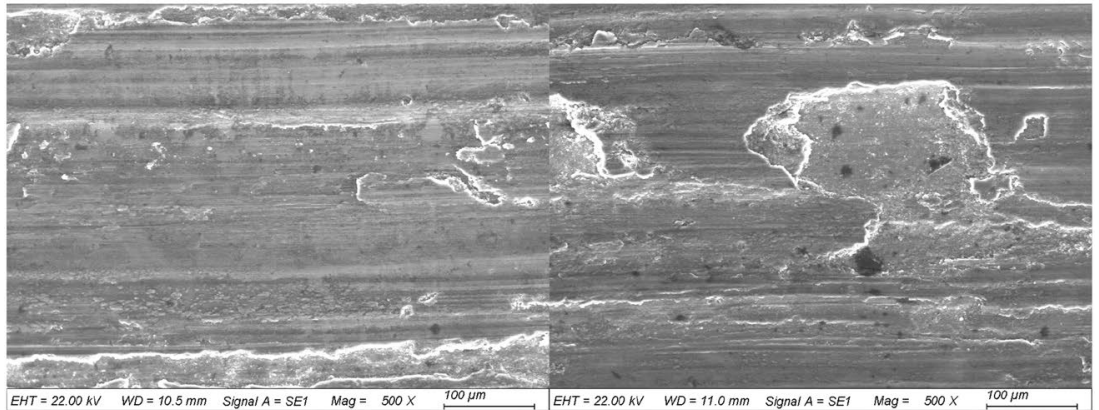

e $25 \mathrm{~N} 2 \mathrm{D}-\mathrm{USBP}$ treated sample f $25 \mathrm{~N}$ original sample

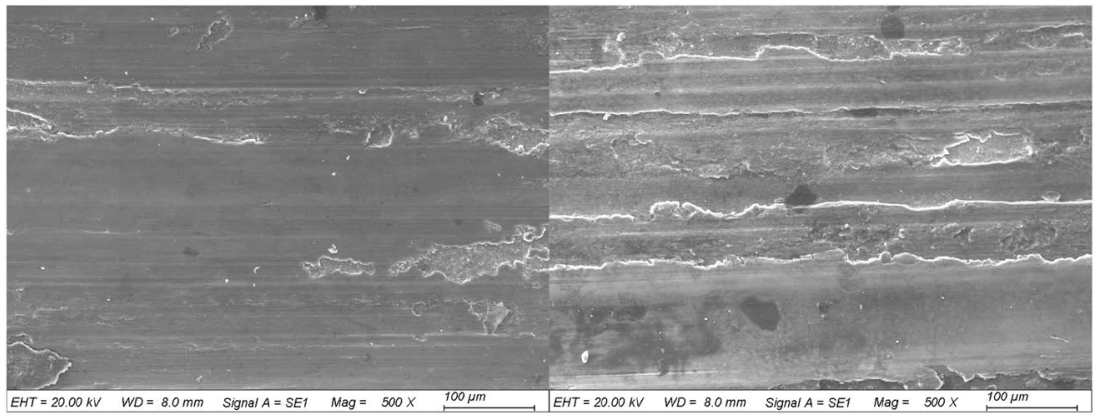

g $35 \mathrm{~N} 2 \mathrm{D}-\mathrm{USBP}$ treated sample $\quad$ h $35 \mathrm{~N}$ original sample

Figure 7 Partial morphology of the dry wear scars 


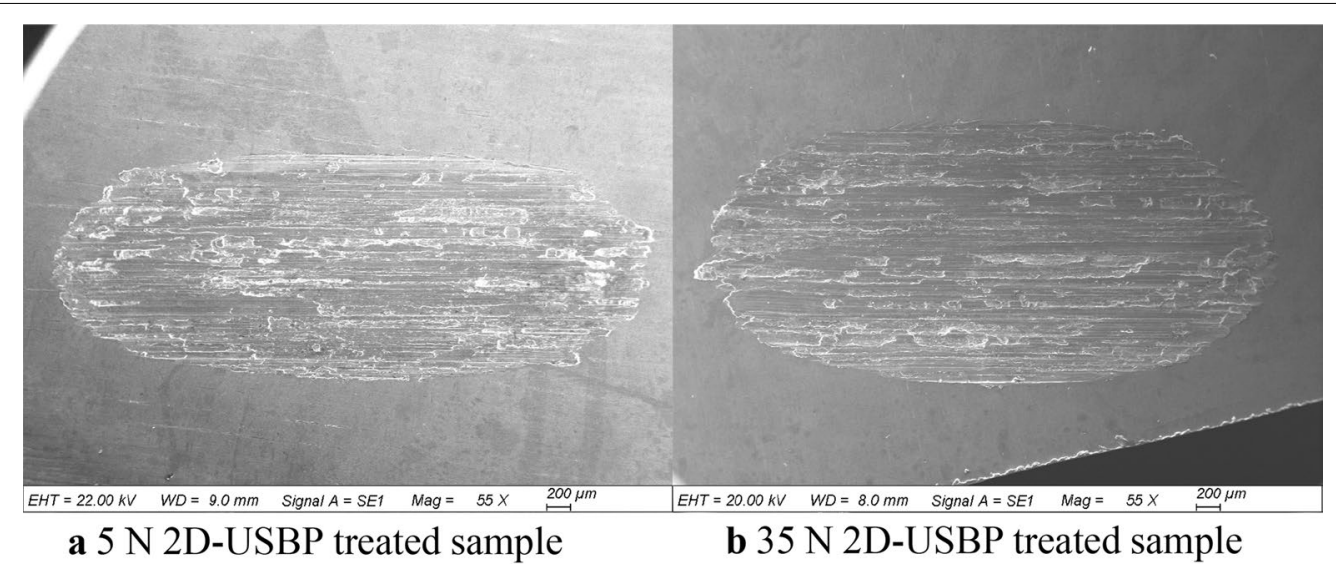

Figure 8 Dry wear morphology

the original sample. Figure 3(a) shows that COF decreases with increasing load, which is because of the non-linear relationship between actual contact area and the load. Figure 3(b) shows that under each load, the coefficient of variation and the interquartile range of $\mathrm{COF}$ of the original sample is smaller than the 2D-USBP treated sample. Dry wear is a pulsating process in which sticking and sliding occur alternately, so COF inevitably undergoes a significant fluctuation phenomenon, the stick-slip phenomenon [28]. COF is calculated by averaging the period. Therefore, in order to study the discrete characteristics of $\mathrm{COF}$, it is necessary to study the discrete characteristics of the friction force and the loading force.

Table 8 shows the statistical results of the friction force and loading force collected during the dry wear process. For the friction force, the interquartile range of the 2D-USBP treated sample is more extensive than the original sample, but the coefficient of variation has no distinct tendency for the two. The interquartile range represents the degree of concentration of the data, and the coefficient of variation represents the degree of dispersion. Compared to the 2D-USBP treated sample, the data near the average of the original sample is more concentrated, while the data far from the average is more divergent. Figure 15 shows the microtopography of the cross-section of the original sample and the 2D-USBP treated sample by a KEYENCE optical microscope. The surface grain of the original sample is coarse. After 2D-USBP, the surface grain has obvious plastic deformation and grain refinement, significantly improving the surface hardness. Previous research by the research group shows that the grains on the surface of 7075-T6 aluminum can be refined to $15 \mathrm{~nm}$ [23]. The 2D-USBP treated sample keep nanocrystalline/ultrafine crystals on the surface, whose chemical activity is higher than the original sample surface. Because of the formation and shearing of the adhesive node during the dry wear process, the 2D-USBP treated sample is more prone to adhesion, resulting in that its friction force is less concentrated than the original sample. The wear mechanism of the original sample is mainly delamination wear, and the generation and expansion of cracks can absorb and release friction energy. Therefore, the data near the average of the original sample is more concentrated, while the data far from the average is more divergent. For the loading force, the interquartile range and the coefficient of variation of the 2D-USBP treated sample is more extensive than the original sample. During the sliding of the upper sample, the peak hardness of the contact point of the 2D-USBP treated sample is higher than the original sample. Therefore, the loading force of the 2D-USBP treated sample is highly volatile. The volatility of the friction coefficient results from the combination of friction force and loading force volatility.

Figures 4 and 5 show that when the load is $5-25 \mathrm{~N}$, the wear scar size of the 2D-USBP treated sample is proportional to the load. This linear relationship has been reported in abrasive wear [28, 29]. Because the wear mechanism of the original sample is delamination wear, there is no such linear relationship. Under the load of 35 $\mathrm{N}$, the linear relationship of the 2D-USBP treated sample is destroyed, and the wear scar size of the 2D-USBP treated sample and the original sample are close. It is because the wear mechanism of the two has changed.

Figures 7(a), (c) shows that for the 2D-USBP treated sample, the wear mechanism under $5 \mathrm{~N}$, and $25 \mathrm{~N}$ load is mainly abrasive wear accompanied by delamination wear. The abrasive particles are pressed into the friction surface by the normal force to form an indentation on the friction surface. Subsequently, under the action of the tangential force, the abrasive particles advance to shear, plow, and cut the friction surface. Figures $7(\mathrm{e}),(\mathrm{g})$ show that as the load 

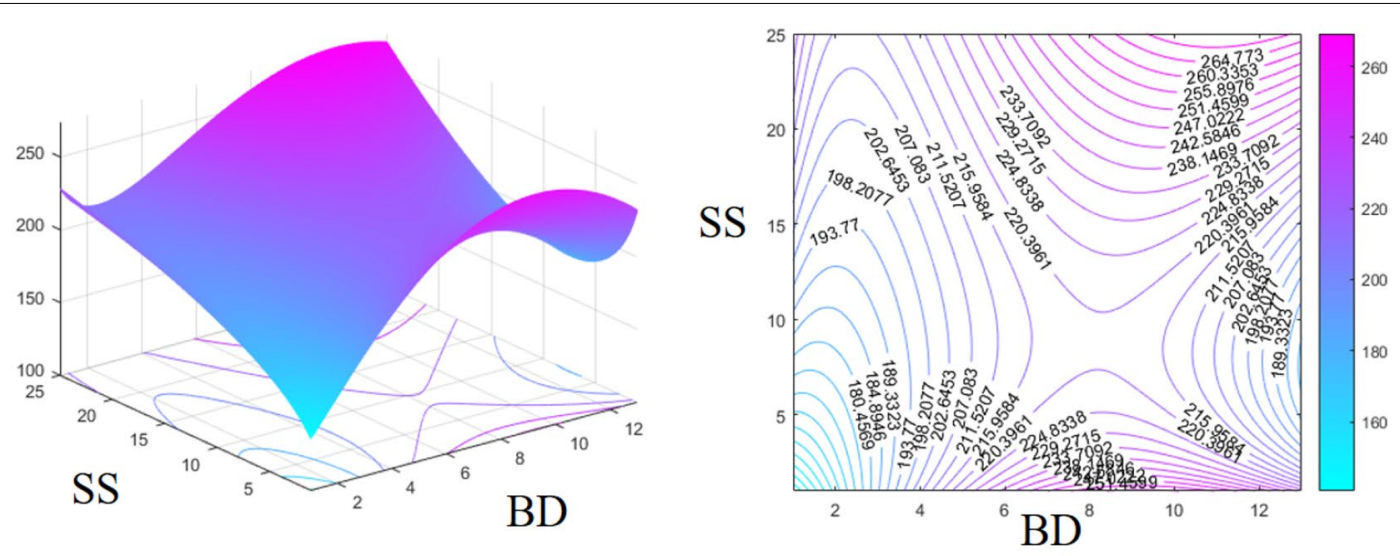

\section{a $\mathrm{FR}=4$}
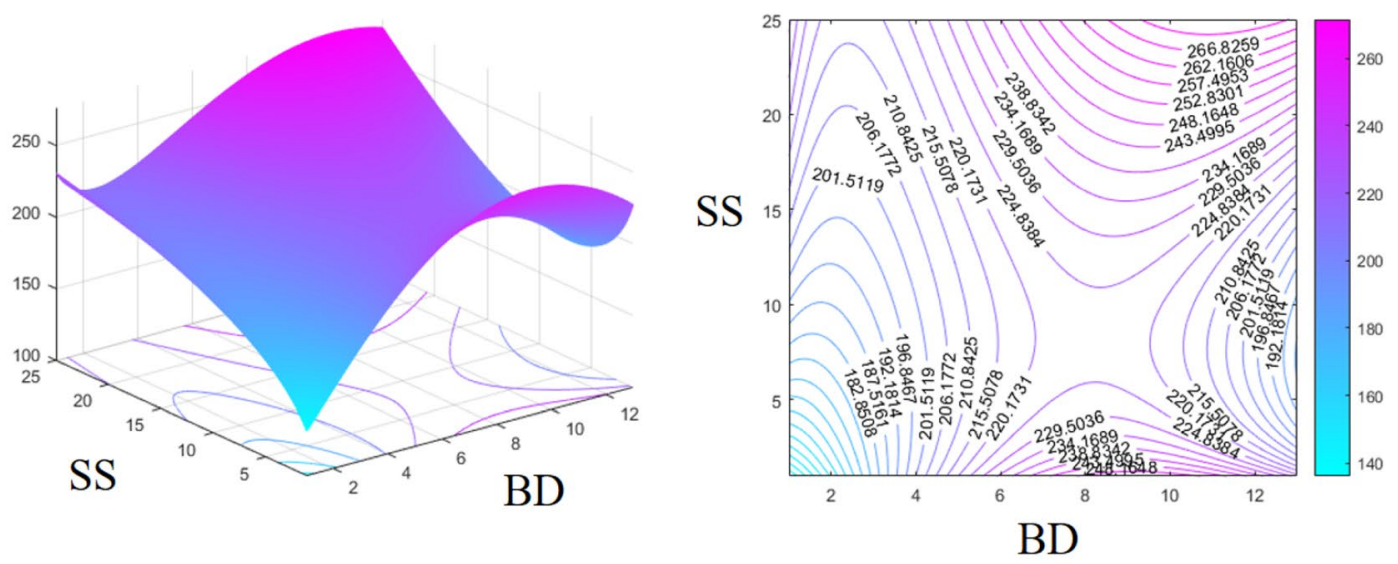

\section{b $\mathrm{FR}=5$}
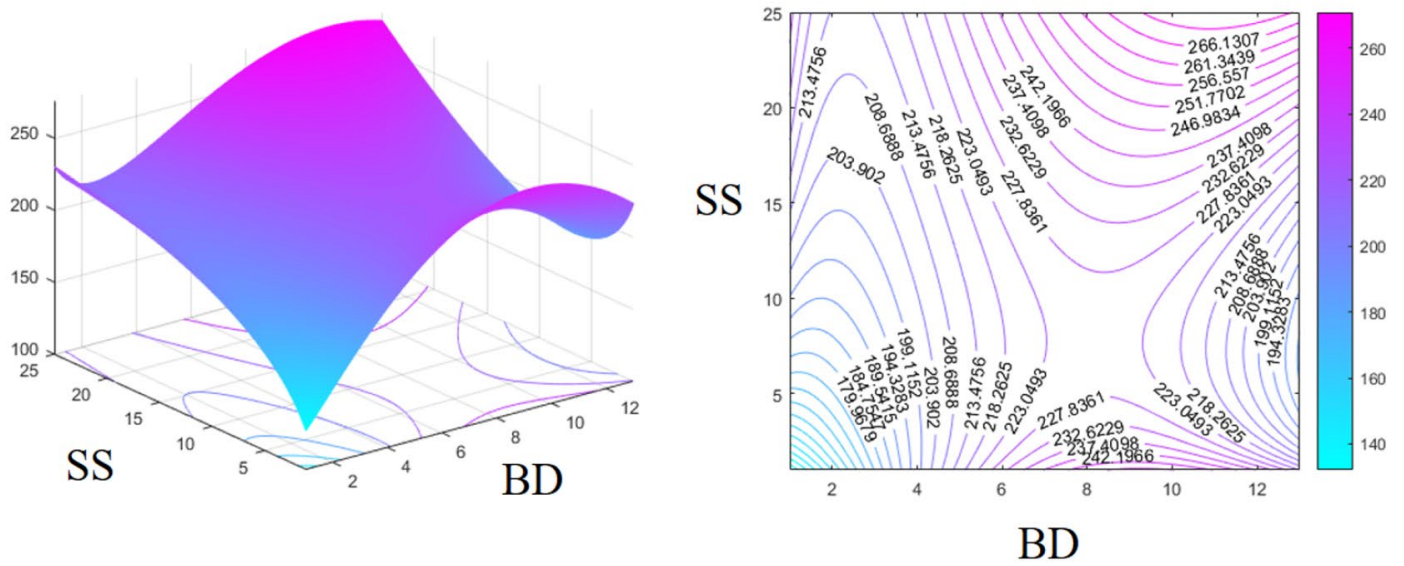

\section{c $\mathrm{FR}=6$}

Figure $9 U_{13}\left(13^{3}\right)$ hardness regression equation 3-D map and contour map. a $F R=4$. b $F R=5$. $\mathbf{c} F R=6$ 

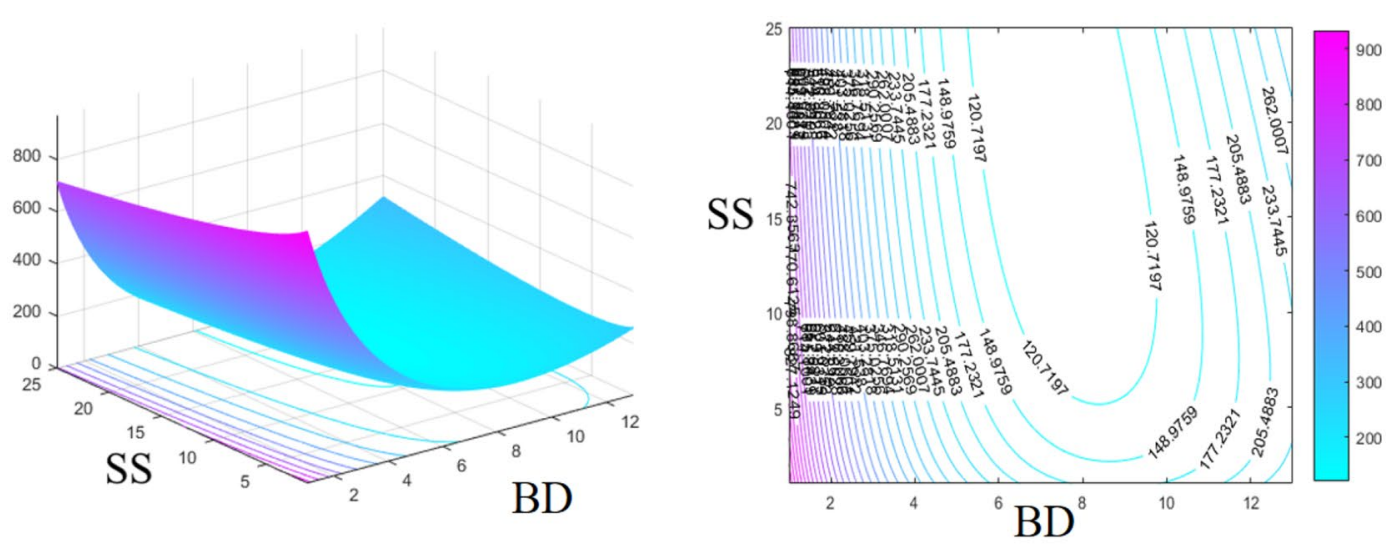

a $\mathrm{FR}=4$
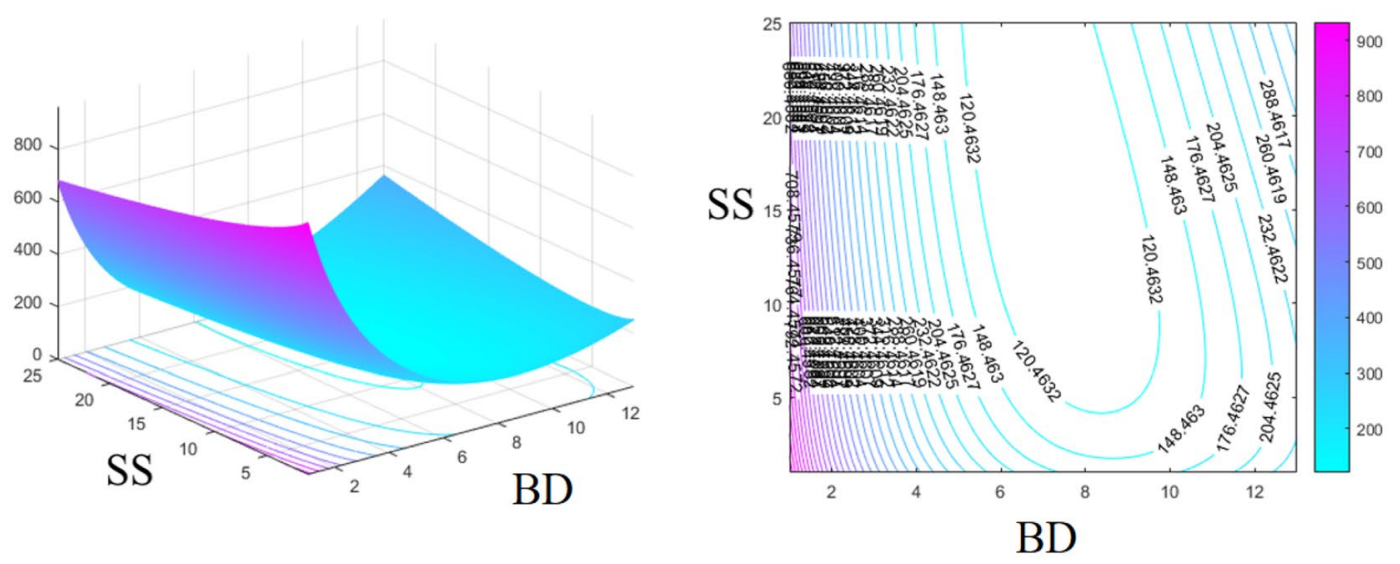

b $\mathrm{FR}=5$
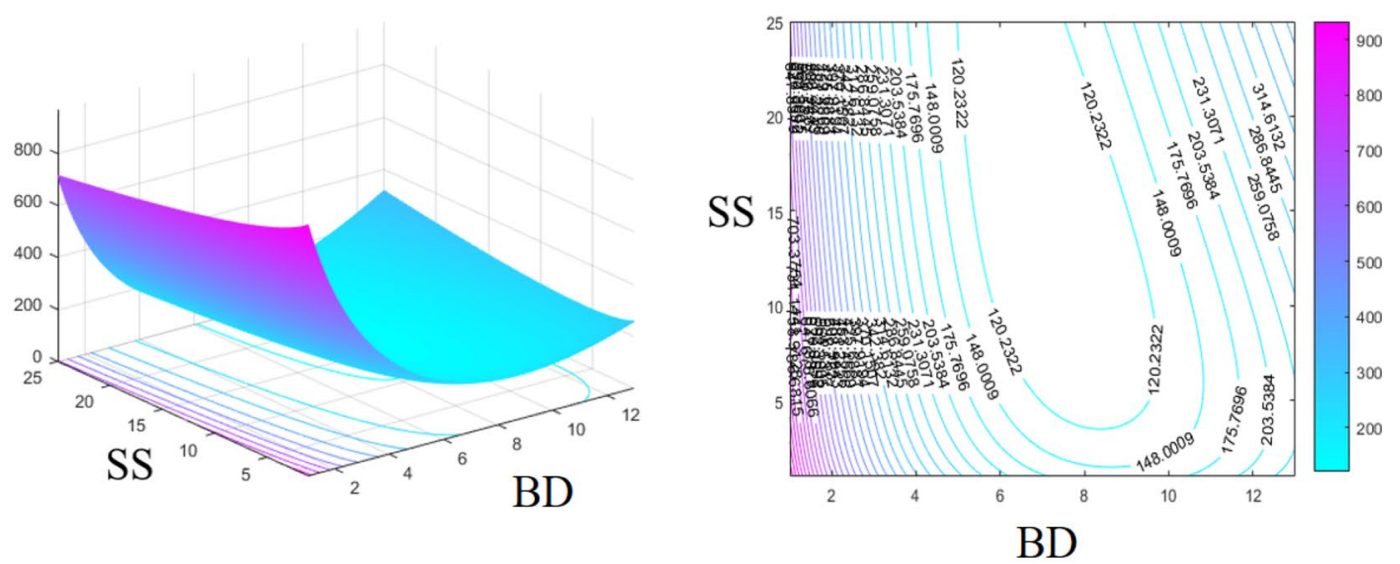

c $\mathrm{FR}=6$

Figure $10 U_{13}\left(13^{3}\right) S_{a}$ model 3-D map and contour map. a $F R=4$. b FR=5. c FR=6 
Table 5 Vickers hardness prediction (HV)

\begin{tabular}{|c|c|c|c|c|c|c|c|c|c|}
\hline \multirow[t]{2}{*}{ BD } & \multicolumn{9}{|l|}{ SS } \\
\hline & 17 & 18 & 19 & 20 & 21 & 22 & 23 & 24 & 25 \\
\hline 7 & 232.24 & 234.52 & 236.95 & 239.50 & 242.17 & 244.95 & 247.83 & 250.80 & 253.87 \\
\hline 8 & 236.79 & 239.55 & 242.48 & 245.55 & 248.77 & 252.12 & 255.60 & 259.19 & 262.88 \\
\hline 9 & 238.86 & 242.15 & 245.64 & 249.30 & 253.13 & 257.11 & 261.23 & 265.49 & 269.87 \\
\hline 10 & 238.09 & 241.97 & 246.07 & 250.36 & 254.85 & 259.50 & 264.32 & 269.29 & 274.39 \\
\hline 11 & 234.22 & 238.73 & 243.48 & 248.46 & 253.64 & 259.01 & 264.56 & 270.27 & 276.14 \\
\hline
\end{tabular}

Table $6 U_{7}\left(7^{2}\right)$ uniform design table

\begin{tabular}{|c|c|c|c|c|c|c|c|c|}
\hline Serial number & $\begin{array}{l}\text { Burnishing depth } \\
(\mathrm{mm})\end{array}$ & $\begin{array}{l}\text { Spindle speed }(r / \\
\text { min) }\end{array}$ & $\begin{array}{l}\text { Feed rate }(\mathrm{mm} / \\
\mathrm{min})\end{array}$ & BD & SS & $\mathrm{FR}$ & $\begin{array}{l}\text { Surface } \\
\text { roughness } S_{a}(n m)\end{array}$ & $\begin{array}{l}\text { Vickers } \\
\text { hardness } \\
\text { (HV) }\end{array}$ \\
\hline 1 & 0.18 & 5200 & 25 & 6.00 & 26 & 5 & 112.756 & 231 \\
\hline 2 & 0.2 & 4600 & 25 & 6.66 & 23 & 5 & 106.624 & 235 \\
\hline 3 & 0.22 & 5600 & 25 & 7.33 & 28 & 5 & 101.996 & 244 \\
\hline 4 & 0.24 & 5000 & 25 & 8.00 & 25 & 5 & 76.138 & 252 \\
\hline 5 & 0.26 & 4400 & 25 & 8.66 & 22 & 5 & 98.135 & 246 \\
\hline 6 & 0.28 & 5400 & 25 & 9.33 & 27 & 5 & 82.497 & 233 \\
\hline 7 & 0.3 & 4800 & 25 & 10.0 & 24 & 5 & 130.897 & 225 \\
\hline
\end{tabular}

increases, the abrasive wear phenomenon gradually weakens, hardly observed at the $35 \mathrm{~N}$ load. As the load increases, the temperature at the friction zone gradually increases, softening the upper sample and the friction surface. The increase in the temperature of the friction pair reduces the hardness of the abrasive particles, improves the ductility of the friction surface, and reduces the degree of abrasive wear. At $35 \mathrm{~N}$ load, thermal wear causes the surface to "smear", transfers and rubs off surface particles [30].

Figures 7(b), (d), (f) show that the delamination wear, generated thin and long lamellar wear debris, causes irregular detachment areas on the surface of the original sample. When the friction pairs slide against each other, the rough peak on the soft surface is easily deformed and broken under the cyclic load to form a smooth surface. During the dry wear process, the shear deformation accumulates, causing dislocation accumulation at a certain depth below the surface, which leads to the formation of cracks or voids. The crack extends in a direction parallel to the surface. When the crack propagates to a critical length, the material between the crack and the surface will peel off in the form of flaky wear debris. Figure 7(h) shows that the wear mechanism is a combination of thermal wear and delamination wear, which is similar to the mechanism of Figure $7(\mathrm{~g})$ and not repeated here.

The wear mechanisms between the 2D-USBP treated sample and the original sample are different because 2D-USBP changed the mechanical properties and microstructure of the 7075-T6 aluminum surface. Figure 14 shows that 2D-USBP improves the three-dimensional profile of the sample surface, making the material surface smoother. The coarse grains and large roughness of the original sample surface caused significant discontinuities in composition and morphology, which constituted the source of stress concentration and caused the surface to experience higher stress cycles. 2D-USBP improves the uniformity of the sample surface and reduces stress concentration. Under the lower load, 2D-USBP improves the surface quality of the sample, resulting in reduced wear weight loss and reduced wear scar size. However, under the higher load, a large amount of heat is generated between the friction pairs, changing the microstructure and mechanical properties of the sample surface. Therefore, the difference in weight loss and wear scar size between the original sample and the 2D-USBP treated sample under the higher load is smaller than the difference between the two under the lower load.

\section{Conclusions}

(1) A novel high-efficiency surface burnishing tool is proposed, combined with a two-dimensional ultrasonic vibration platform to improve the surface properties of 7075-T6 aluminum. $U_{13}\left(13^{3}\right)$ and $U_{7}\left(7^{2}\right)$ uniform design tables are established with burnishing depth, spindle speed and feed rate as control parameters, and surface roughness $S_{\mathrm{a}}$, 


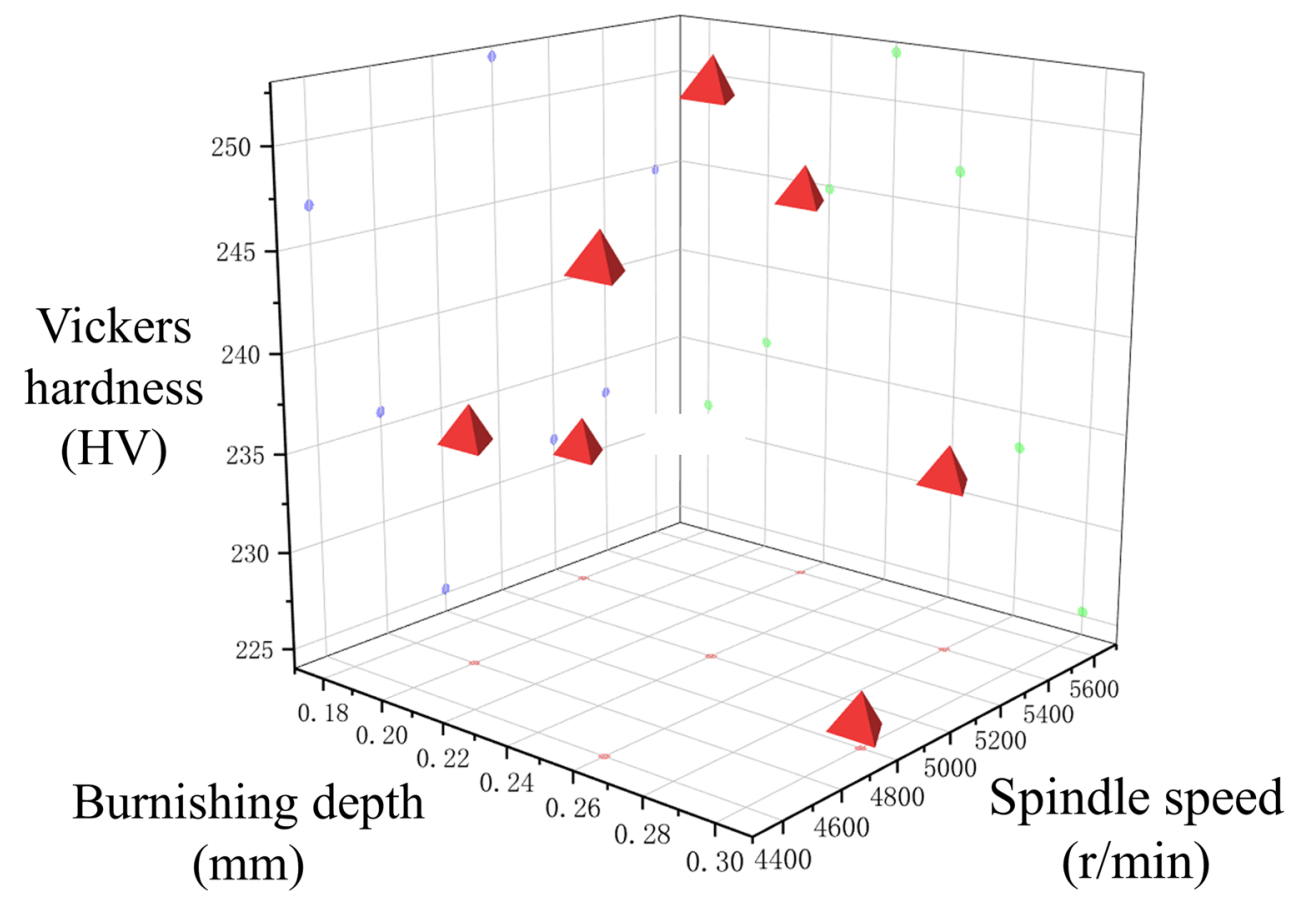

a Vickers hardness

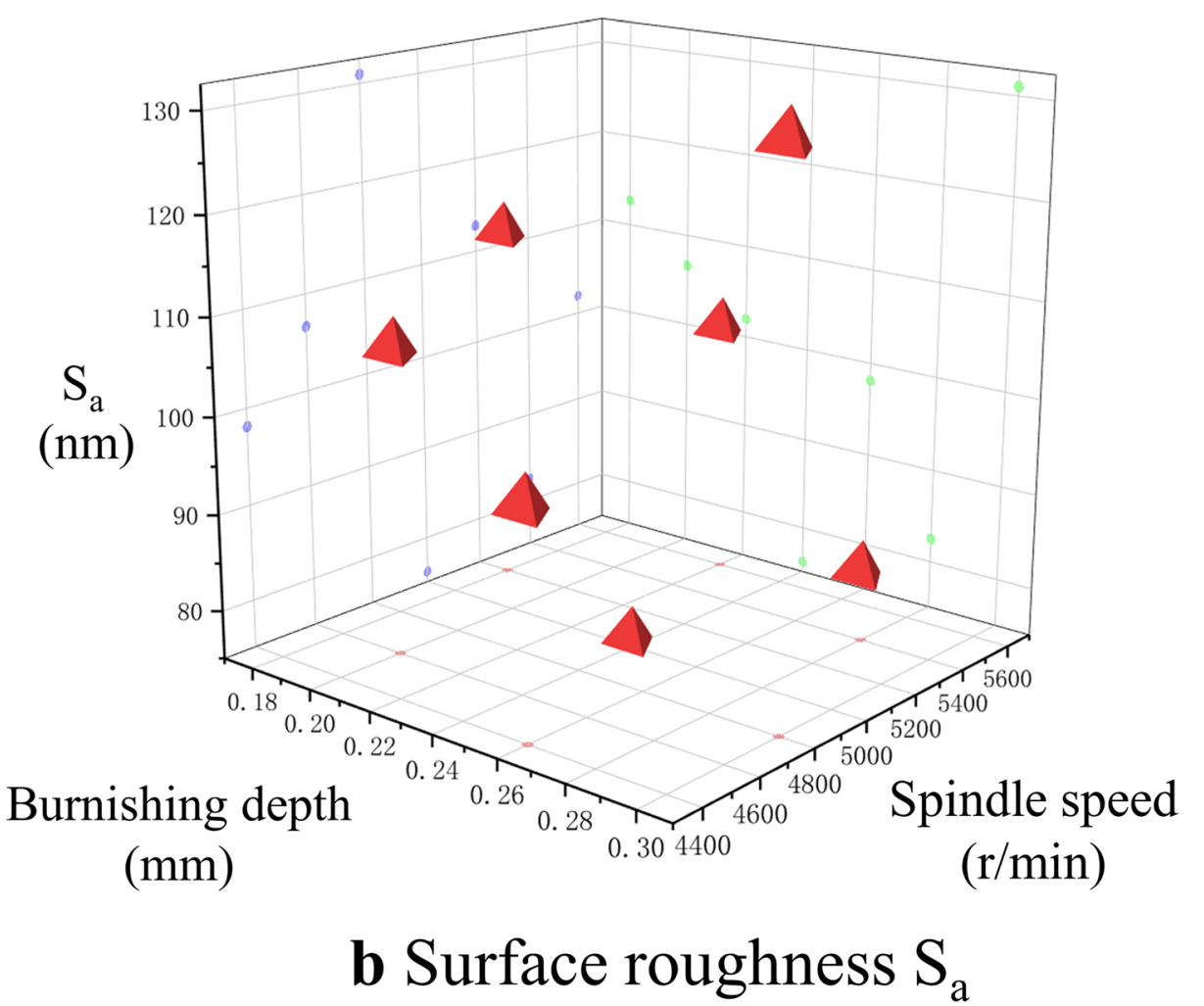

Figure 11 Experiment results of the $U_{7}\left(7^{2}\right)$ uniform design table. a Vickers hardness. b Surface roughness $S_{a}$ 
Table 7 Significant analysis of regression equations

\begin{tabular}{|c|c|c|c|c|c|c|}
\hline Model & & Sum of squares & $\mathrm{d} f$ & Mean square & $F$ & Significant \\
\hline \multirow[t]{4}{*}{$R$} & Regression & 3343505.62 & 4 & 835876.407 & 5231.812 & $.000 b$ \\
\hline & Residual & 479.30 & 3 & 159.768 & & \\
\hline & Total & 3343984.93 & 7 & & & \\
\hline & $R=0.999, R^{2}=$ & isted $R^{2}=0.996$ & & & & \\
\hline \multirow[t]{4}{*}{ V } & Regression & 348.635 & 2 & 174.317 & 8.543 & $.036 b$ \\
\hline & Residual & 81.621 & 4 & 20.405 & & \\
\hline & Total & 430.255 & 6 & & & \\
\hline & $R=0.900, R^{2}=$ & sted $R^{2}=0.715$ & & & & \\
\hline
\end{tabular}

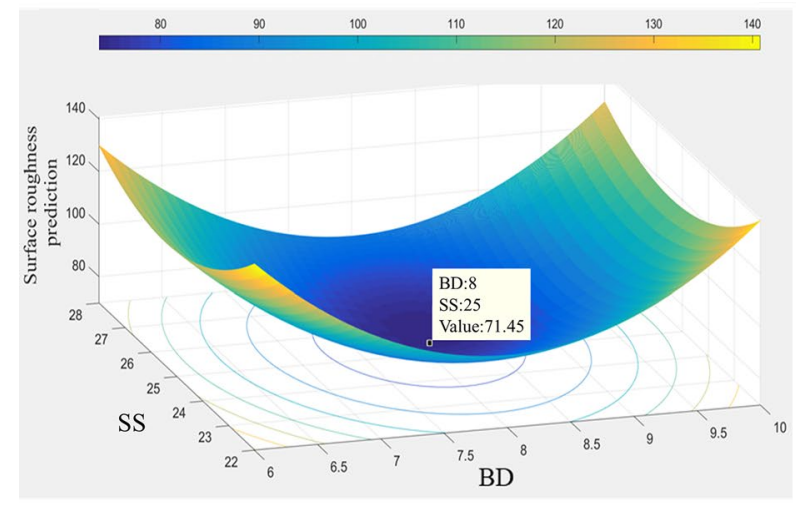

a 3-D map

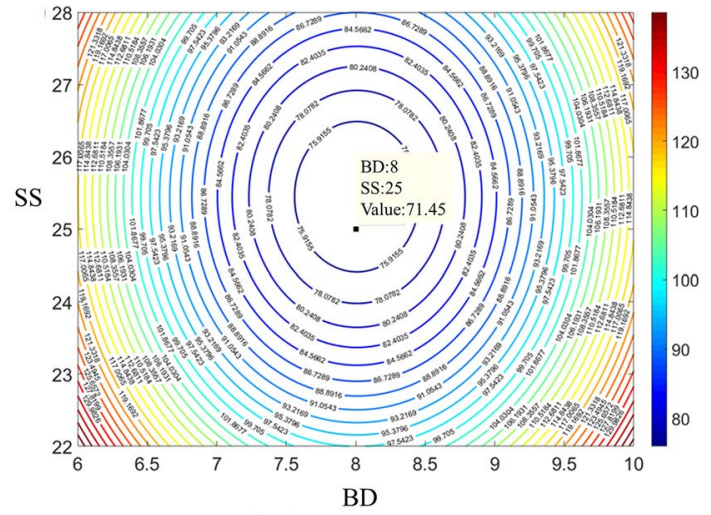

b Contour map

Figure $12 U_{7}\left(7^{2}\right)$ surface roughness regression equation. a 3-D map. b Contour map

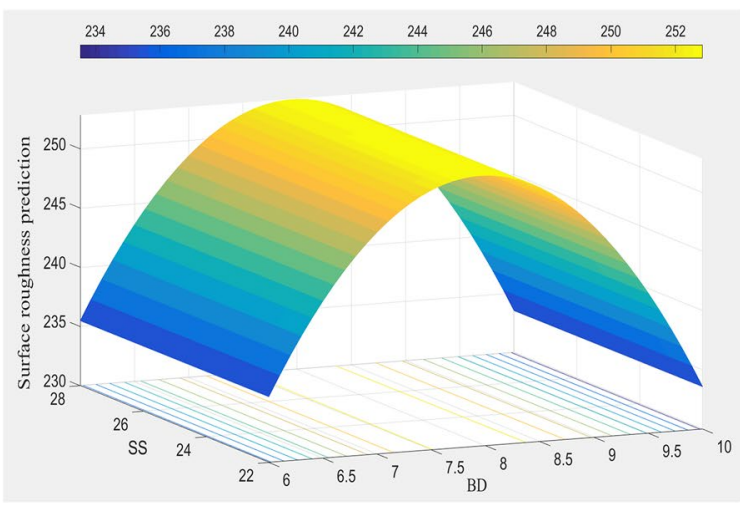

a 3-D map

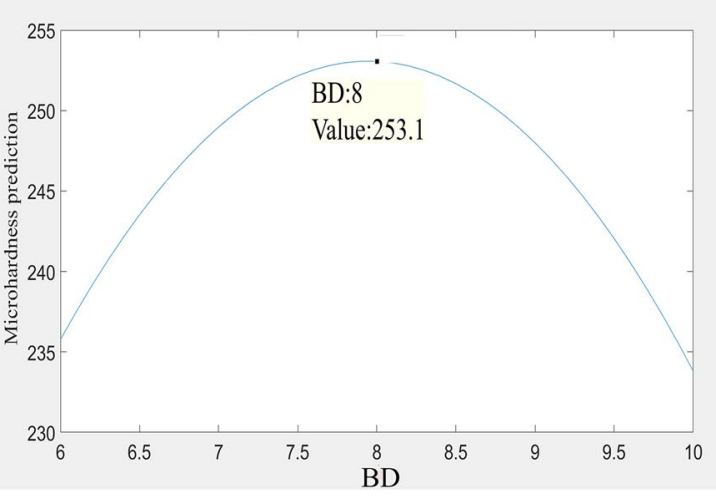

b Contour map

Figure $13 U_{7}\left(7^{2}\right)$ hardness regression equation. a 3-D map. b Contour map 


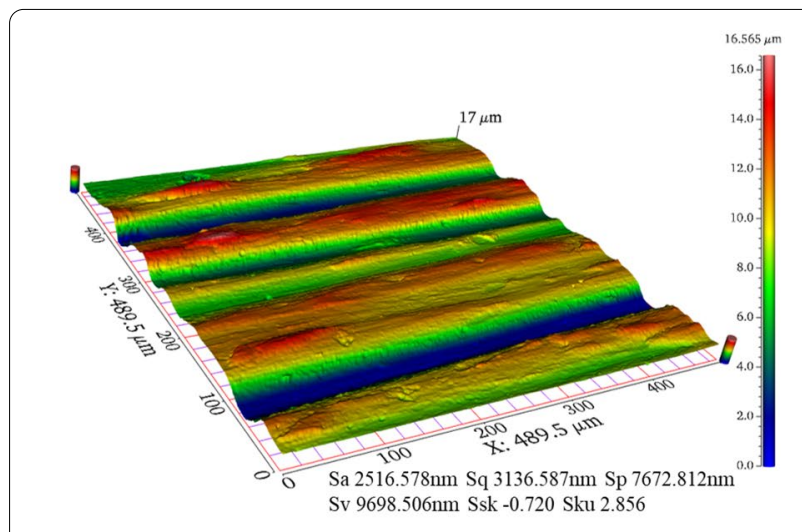

a Original sample

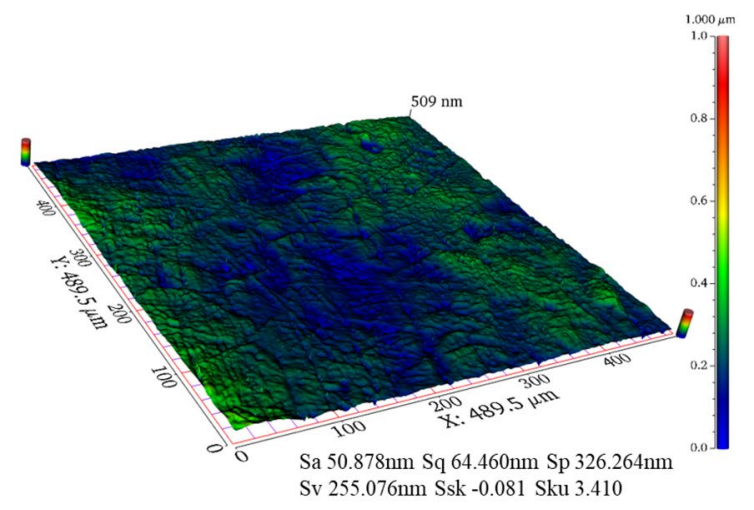

b 2D-USBP treated sample

Figure 14 Surface 3-D profile. a Original sample. b 2D-USBP treated sample

Table 8 Friction and loading force statistics

\begin{tabular}{|c|c|c|c|c|c|c|c|c|c|}
\hline & & T5 N & $05 \mathrm{~N}$ & $\mathrm{~T} 15 \mathrm{~N}$ & $015 \mathrm{~N}$ & $\mathrm{~T} 25 \mathrm{~N}$ & $\mathrm{O} 25 \mathrm{~N}$ & T35 N & O35 N \\
\hline \multirow[t]{3}{*}{ Friction force } & Average value & 2.22 & 2.25 & 6.20 & 6.22 & 10.18 & 10.33 & 14.34 & 14.49 \\
\hline & Interquartile range & 0.725 & 0.691 & 2.876 & 2.223 & 4.311 & 4.185 & 6.960 & 5.762 \\
\hline & Coefficient of variation & 0.262 & 0.262 & 0.324 & 0.297 & 0.333 & 0.331 & 0.354 & 0.355 \\
\hline \multirow[t]{3}{*}{ Loading force } & Average value & 4.99 & 4.99 & 14.99 & 14.99 & 24.99 & 24.99 & 34.97 & 34.95 \\
\hline & Interquartile range & 0.648 & 0.585 & 1.503 & 1.401 & 2.456 & 2.036 & 2.964 & 2.254 \\
\hline & Coefficient of variation & 0.086 & 0.070 & 0.059 & 0.051 & 0.052 & 0.047 & 0.048 & 0.041 \\
\hline
\end{tabular}

T means the 2D-USBP treated sample, O means the original sample
Vickers hardness as evaluation indicators. Based on the results of the uniform design tables, surface quality regression equations are established to optimize 2D-USBP processing parameters. The optimal machining strategy for 7075-T6 is $0.24 \mathrm{~mm}$ burnishing depth, $5000 \mathrm{r} / \mathrm{min}$ spindle speed, and $25 \mathrm{~mm} / \mathrm{min}$ feed rate.

(2) 2D-USBP reduced the surface roughness $S_{a}$ of the 7075-T6 aluminum from 2517.758 to $50.878 \mathrm{~nm}$ and increased the Vickers hardness of the 7075T6 aluminum surface from 167 to $252 \mathrm{HV}$. The original texture of the sample surface disappeared, the surface became flat, and the surface hardness increased. Therefore, under different loads, the friction coefficient of the 2D-USBP treated sample is smaller than the original sample.

(3) Dry wear experiments show that under the lower load, the wear mechanism of the 2D-USBP treated sample is abrasive wear, and the original sample is delamination wear. The wear weight loss and the wear scar size of the 2D-USBP treated sample are much smaller than the original sample. 2D-USBP reduces the unevenness of the sample surface, refines the grains in the surface layer, and improves the surface hardness, making the sample has a better wear-resistance. Under the higher load, the accumulation of frictional heat transforms the wear mechanism of the original sample and the 2D-USBP treated sample into thermal wear, which reduces the wear weight loss and the wear scar size gap between the two samples. 


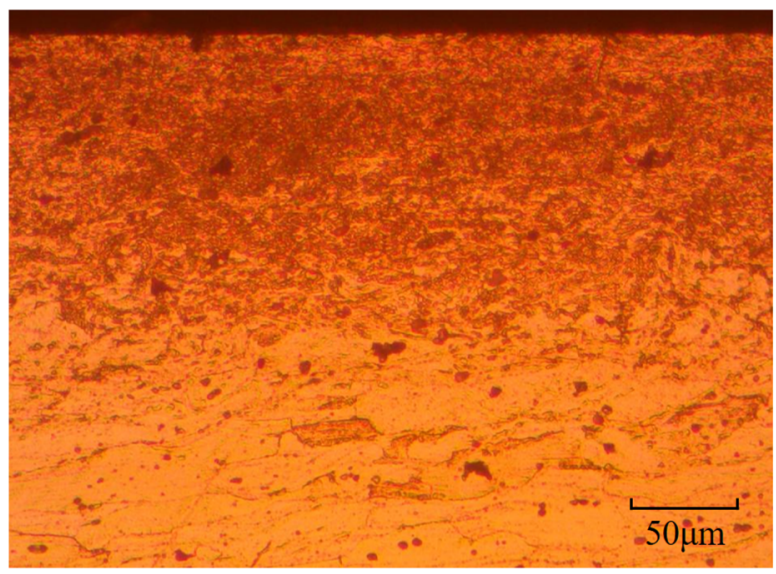

a Original sample

Figure 15 Microtopography of the cross-section of 7075-T6 aluminum. a

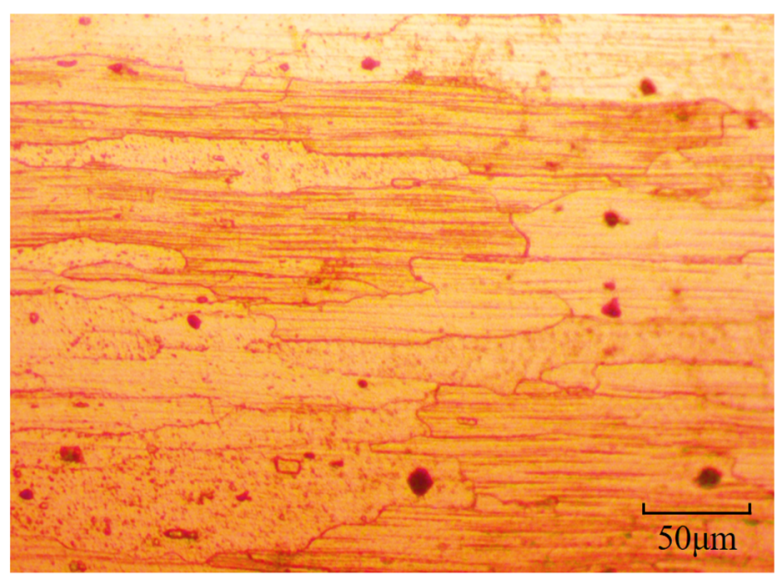

b 2D-USBP treated sample

Original sample. b 2D-USBP treated sample

\section{Acknowledgements}

The authors sincerely thank to Professor Mingxue Shen of East China Jiaotong University for his assistance during manuscript preparation.

\section{Authors' Contributions}

ZP was in charge of the whole trial; ZZ wrote the manuscript; GY conducted the experiments; ZZ and QZ conceived and designed the research; CD and GP revised the manuscript. All authors read and approved the final manuscript.

\section{Authors' Information}

Zhenyu Zhou, born in 1993, is currently a PhD candidate at Key Laboratory of Special Purpose Equipment and Advanced Processing Technology (Zhejiang University of Technology), Ministry of Education, China. He received his bachelor degree from Zhejiang University of Technology, China, in 2016. His research interests include surface engineering. E-mail: zhouzy@zjut.edu.cn.

Qiuyang Zheng, born in 1995, is currently a PhD candidate at Key Laboratory of Special Purpose Equipment and Advanced Processing Technology (Zhejiang University of Technology), Ministry of Education, China. He received his bachelor degree from Zhejiang University of Technology, China, in 2017. His research interests include surface engineering. E-mail: m15990049659@163.com.

Cong Ding, born in 1990, is currently an associate professor at School of Mechanical Engineering, Zhejiang University of Technology, China. She received her bachelor degree from China University of Mining and Technology, in 2014 and PhD degree from China University of Mining and Technology, in 2019. Her research interests include surface engineering and tribology. E-mail: dcong105@126.com.

Guanglei Yu, born in 1994, is currently a master candidate at Key Laboratory of Special Purpose Equipment and Advanced Processing Technology (Zhejiang University of Technology), Ministry of Education, China. E-mail: glyu33@zjut.edu.cn.

Guangjian Peng, born in 1986, is currently an associate professor at School of Mechanical Engineering, Zhejiang University of Technology, China. His research interests include micro-nano manufacturing. E-mail: penggj@zjut.edu.cn.

Zhongyu Piao, born in 1982, is currently an associate professor at School of Mechanical Engineering, Zhejiang University of Technology, China. His research interests include surface engineering and tribology. E-mail: piaozy@zjut.edu. $\mathrm{cn}$.

\section{Funding}

Supported by National Natural Science Foundation of China (Grant Nos. 51675483, 51705028), Fundamental Research Funds for the Provincial Universities of Zhejiang (Grant No. RF-A2019008), Foundations (Grant Nos. 61409230606, EM2015042003)

\section{Competing Interests}

The authors declare no competing financial interests.

\section{Author Details}

${ }^{1}$ College of Mechanical Engineering, Zhejiang University of Technology, Hangzhou 310012, China. ${ }^{2}$ Key Laboratory of Special Purpose Equipment and Advanced Processing Technology, Ministry of Education and Zhejiang Province, Zhejiang University of Technology, Hangzhou 310012, China.

Received: 12 May 2020 Revised: 16 December 2020 Accepted: 16 January 2021

Published online: 10 February 2021

\section{References}

[1] Y Ni, L Fu, Z Shen, et al. Role of tool design on thermal cycling and mechanical properties of a high-speed micro friction stir welded 7075-T6 aluminum alloy. Journal of Manufacturing Processes, 2019, 48: 145-153.

[2] S Zhang, T Zhang, YTHe, et al. Long-term atmospheric pre-corrosion fatigue properties of epoxy primer-coated 7075-T6 aluminum alloy structures. International Journal of Fatigue, 2019, 129: 105225.

[3] ZY Piao, ZZZ Zhou, J Xu, et al. Use of X-ray computed tomography to investigate rolling contact cracks in plasma sprayed Fe-Cr-B-Si coating. Tribology Letters, 2019, 67(1): 11.

[4] H Sun, A H Li, Y H Zhou, et al. Dry wear characteristics of machined ZL109 aluminum-silicon alloy surface under unidirectional and reciprocating rolling-contact friction. Surface Topography-Metrology and Properties, 2020, 8(1): 015001.

[5] Y J Wang, Z Y Li, Y Q Zhang, et al. Cold arc cladding of aluminum coatings on AZ61 magnesium alloy: A comparative study. Surface \& Coatings Technology, 2019, 375: 442-457.

[6] H Maruno, A Nishimoto. Effect of number of multilayer repetitions and thickness ratio on coating properties of Si-DLC/DLC multilayer coatings on aluminum alloys. Journal of the Japan Institute of Metals and Materials, 2019, 83(3): 82-86. 
[7] SY Xie, R D Li, T C Yuan, et al. Laser cladding assisted by friction stir processing for preparation of deformed crack-free $\mathrm{Ni}$-Cr-Fe coating with nanostructure. Optics and Laser Technology, 2018, 99: 374-381.

[8] X H Zhao, Y Q Zhao, D S Xu, et al. Effect of gradient nanostructure on plasma sulfonitrocarburizing of $42 \mathrm{MnCr} 52$ steel. Tribology Transactions, 2020, 63(1): 133-143.

[9] ZY Piao, B Xu, H D Wang, et al. Rolling contact fatigue behavior of thermal-sprayed coating: A review. Critical Reviews in Solid State and Materials Sciences, 2019, 45(6): 429-456.

[10] C Yang, M Q Li. 3D surface morphology and performance of TC17 processed by surface severe plastic deformation. Surface \& Coatings Technology, 2020, 397: 125995.

[11] J B Liu, X H Zhang, Z Y Cui, et al. Effects of ultrasonic surface rolling processing and plasma nitriding on the fretting wear behavior of Inconel 690TT. Surface \& Coatings Technology, 2020, 402:126312.

[12] L Hackel, J R Rankin, A Rubenchik, et al. Laser peening: A tool for additive manufacturing post-processing. Additive Manufacturing, 2018, 24 67-75.

[13] C H Chen, R M Ren, X J Zhao, et al. Surface nanostructures in commercial pure Ti induced by high energy shot peening. Transactions of Nonferrous Metals Society of China, 2004, 14: 215-218.

[14] M Duan, L Luo, Y Liu. Microstructural evolution of AZ31 Mg alloy with surface mechanical attrition treatment: Grain and texture gradient. Journal of Alloys and Compounds, 2020, 823:153691.

[15] M Sato, N Tsuji, Y Minaminob, et al. Formation of nanocrystalline surface layers in various metallic materials by near surface severe plastic deformation. Science and Technology of Advanced Materials, 2004, 5(12): 145-152

[16] J Yang, D X Liu, X H Zhang, et al. The effect of ultrasonic surface rolling process on the fretting fatigue property of GH4169 superalloy. International Journal of Fatigue, 2020, 133:105373.

[17] C G He, H H Ding, L B Shi, et al. On the microstructure evolution and nanocrystalline formation of pearlitic wheel material in a rolling-sliding contact. Materials Characterization, 2020, 164:110333.

[18] J Zhao, W Xia, N Li, et al. A gradient nano/micro-structured surface layer on copper induced by severe plasticity roller burnishing. Transactions of Nonferrous Metals Society of China, 2014, 24(2): 441-448.
[19] Y C Lin, SW Wang, HY Lai. The relationship between surface roughness and burnishing factor in the burnishing process. International Journal of Advanced Manufacturing Technology, 2004, 23(9-10): 666-671.

[20] G Rotella, S Rinaldi, L Filice. Roller burnishing of Ti6Al4V under different cooling/lubrication conditions and tool design: effects on surface integrity. International Journal of Advanced Manufacturing Technology, 2020, 106(1-2): 431-440.

[21] A T Bozdana, N N Z Gindy, H Li. Deep cold rolling with ultrasonic vibrations - A new mechanical surface enhancement technique. International Journal of Machine Tools \& Manufacture, 2005, 45(6): 713-718.

[22] J R Yuan, J Xu, Z Z Zhou, et al. Study on wear behavior of gradient nanocrystalline structure on pure copper surface induced by burnishing. Journal of Mechanical Engineering, 2017, 53(24): 49-54. (in Chinese)

[23] ZY Zhou, G L Yu, Q Y Zheng, et al. Wear behavior of 7075-aluminum after ultrasonic-assisted surface burnishing. Journal of Manufacturing Processes, 2020, 51: 1-9.

[24] R Teimouri, Z Q Liu. An analytical prediction model for residual stress distribution and plastic deformation depth in ultrasonic-assisted single ball burnishing process. International Journal of Advanced Manufacturing Technology, 2020,111(1-2): 127-147.

[25] B C Jiang, M Y Ai. Construction of uniform designs without replications. Journal of Complexity, 2014, 30(1), 98-110.

[26] CX Ma, KT Fang. A new approach to construction of nearly uniform designs. International Journal of Materials \& Product Technology, 2004, 20(1-3): 115-126.

[27] S Zhang, T B Ma, A Erdemir, et al. Tribology of two-dimensional materials: From mechanisms to modulating strategies. Materials Today, 2019, 26: 67-86.

[28] P A Thompson, M O Robbins. Origin of stick-slip motion in boundary lubrication. Science, 1990, 250(4982): 792-794.

[29] D A Stewart, P H Shipway, D G McCartney. Abrasive wear behaviour of conventional and nanocomposite HVOF-sprayed WC-Co coatings. Wear, 1999, 225: 789-798.

[30] C S Li, X H Liu, G D Wang, et al. Experimental investigation on thermal wear of high speed steel rolls in hot strip rolling. Materials Science and Technology, 2002, 18(12): 1581-1584.

\section{Submit your manuscript to a SpringerOpen ${ }^{\circ}$ journal and benefit from:}

- Convenient online submission

- Rigorous peer review

- Open access: articles freely available online

- High visibility within the field

Retaining the copyright to your article

Submit your next manuscript at springeropen.com 